\title{
The Wells of Gas and Gas Condensate Reservoirs in the South- Eastern Part of the Bukhara-Khiva Region and Methods for Increasing Their Productivity
}

\author{
Khayitov Odiljon Gafurovich \\ Doctor of Geological and Mineralogical Sciences, Academician of the Turan Academy of Sciences, Head of the \\ Department of Mining, Tashkent State Technical University, Tashkent, Uzbekistan \\ Corresponding author email: odiljon.hayitov@tdtu.uz
}

\begin{abstract}
The article examines the methods of increasing the productivity of wells of gas and gas condensate reservoirs in the south-eastern part of the Bukhara-Khiva region (BHR). The role of gas calculation methods in determining the gas reserve of Mesopotamia in sveza with an increase in the share of gas reserves from 1 to 10 million tons of conventional fuel is shown. Certain difficulties have been identified in the issue of reliable determination of gas reserves in the limited fund of wells and large ranges of changes in calculated parameters. The determining significance of the value of gas reserves in calculating the forecast indicators of the development and technologies of their extraction is justified. It is established that increasing the degree of reliability of calculating gas reserves ensures the efficiency of its extraction, as well as the rational use of material and technical resources and financial capabilities of the enterprise. The advantages of such methods for determining gas reserves as the volume method, the material balance method, and static models are disclosed. A specific description of each of these methods and their application for calculating gas reserves at the Northern Guzar field is given.
\end{abstract}

Keywords---material balance, parameter, productivity, resource, statistical

\section{Introduction}

A sufficiently high degree of knowledge of the carbonate formation in the southeastern part of the Bukhara-Khiva region (BHR) reduces the likelihood of discovering large and medium-sized hydrocarbon deposits. However, at the same time, the share of discoveries of small deposits containing gas reserves from 1 to 10 million tons of equivalent fuel (TEF) is increasing. An example is gas and gas condensate fields discovered in recent years Tavakkal, Nishan, Divkhan, Ernazar, Chigil, Nazarkuduk, Southern Girsan, Talimarjon, etc. In these fields, certain difficulties arise in the issue of reliably establishing gas reserves due to the limited number of wells and large ranges of variation in design parameters. The amount of gas reserves is the basis for determining the forecast indicators of development and technologies for their extraction. The unreliability of this parameter, both in the direction of decreasing and increasing it in the development process, requires a revision of previously obtained technological solutions, unjustified consumption of material and technical resources and financial costs, which reduces the efficiency of exploitation of natural gas fields (Mayer \& Butler, 1993; Kadanoff, 1990).

Increasing the degree of reliability in calculating gas reserves contributes to the development of more substantiated design solutions and allows not only to initially increase the efficiency of its extraction but also to rationally use the material and technical resources and financial capabilities of the enterprise. The application of methods for calculating gas reserves and their reliability depends on the stage of exploration of the field. Currently, depending on the stage of field exploration, the volumetric method, the material balance method (by pressure drop), statistical regularities and geological and mathematical models are widely used to determine gas reserves (Agzamov \& Hayitov, 1999; Xayitov \& Akhrorova, 2002; Akramov et al., 2010; Agzamov \& Khayitov, 2010; Xayitov et al., 2019; Khayitov, 2020; Khayitov et al., 2018; Agzamova et al., 2017). 


\section{Materials and Methods}

However, of this total number, the volumetric method for calculating gas reserves has found the most widespread use, since it can be used at any stage of reservoir development and in any mode of reservoir energy manifestation. The most common factors affecting the accuracy of determining gas reserves by the volumetric method include the following: heterogeneity of the deposit along the section and area; formation anisotropy; the presence of lithological screens; the position of the contact "gas - water" or "gas - oil" in the presence of an oil rim; configuration of the gasbearing area; effective gas-saturated thickness, a saturation of the porous medium with gas, water, oil; fluid mobility threshold, etc. (Aliev \& Bondarenko, 2002; Suchkov, 2006; Grozdev et al., 1988).

The main disadvantage of the volumetric method is that when calculating gas reserves, not only filtration parameters are not taken into account, but low-porosity and low-permeability interlayers are also excluded from the calculation of reserves. The accuracy of determining gas reserves by the material balance method, in general, depends on the regime of the reservoir. High accuracy in determining gas reserves by this method can be guaranteed with full involvement in the development of a deposit that has a gas regime and is homogeneous in terms of reservoir and filtration parameters. Statistical dependencies - patterns of changes in gas production during a period of declining production - are established as a result of generalizing materials on-field development at a late stage of operation. A prerequisite for the application of this method is the absence in the considered period of time (covering the actual period of change in the selection and the time of extrapolation) of changes in the implemented development system (Lifson \& McClintock, 1966; Xu et al., 2016).

This method cannot take into account the changes associated with the commissioning of a booster compressor station (BCS), the rate of water cut in good production, fluctuations in the technological mode of wells to limit or increase the flow rates of the latter, etc. The development of methods for using geological and mathematical models is due to the inaccuracy of other methods that do not take into account the filtration properties of gas-bearing layers when calculating gas reserves. The theoretical basis of this method for calculating gas reserves is the use of a system of equations for non-stationary multiphase three-dimensional filtration in a heterogeneous multilayer anisotropic porous medium of gas, condensate (in gas and oil fields), oil and water (bottom or contour), taking into account gravitational and capillary forces, to describe the development process of a field. Changes in the properties of fluids in a porous medium from pressure, mutual solubility of fluids and other factors in massive and reservoir types (Burlutskaya et al., 2007; Khayitov et al., 2013; Khayitov, 2019).

Difficulties in applying geological and mathematical models for calculating gas reserves are mainly associated with the lack of providing the necessary information about the geological structure of the reservoir, reservoir heterogeneity, measurements of fluid properties during operation and other parameters, especially in the early stages of field development. Let us consider the application of the results of calculating gas reserves by the volumetric pressure drop method and statistical methods for solving development problems on the example of the Northern Guzar field (G'afurovich, 2020; G'ofurovich \& Abdurashidovich, 2021; G'afurovich, 2020; G'ofurovich et al., 2020; G'afurovich et al., 2020; Khayitov, 2020).

The North Guzar gas condensate field was discovered in 1991, the productive horizons XV and XVa are associated with carbonate deposits of the Jurassic. The XV and XVa horizons are represented by dolomites and limestones. The Northern Guzar structure is a brachyanticline of northeastern striking, complicated by tectonic dislocation that intersects the southeastern wing of the fold. The dimensions of the structure along the isohypse are $2600 \mathrm{~m}-6.4 \times 1.7 \mathrm{~km}$, the height is 190-200 m. Horizons XV and XVa represent a single gas-holding tank with a common gas-water contact. Open porosity of dolomites of horizons XV and XVa varies from 1.9 to $13.9 \%$, permeability - from 0.01 to $46.8-10-3$ microns. The open porosity of the limestones in these horizons ranges from 2.2 to $8.5 \%$, and the permeability ranges from 0.01 to 0.5-10-3 microns (Akin \& Hopelain, 1986; Cassiman et al., 2010).

Limestones and dolomites of horizons XV and XVa are characterized as fractured-porous reservoirs. Average values of reservoir pressure are: in the upper part of the deposit $-32.38 \mathrm{MPa}$, in the middle part - $32.9 \mathrm{MPa}$, at the GWC level - 33.04 MPa. The coefficients of anomalous formation pressure vary from 1.075 and 1.078 in the lower part of horizon XVa and to 1.113 and 1.103 in the upper part of horizon XV. The average value of the reservoir temperature in the gas reservoir of horizon $\mathrm{XV}$ is $+111.9^{\circ} \mathrm{C}$, in the middle of horizon $\mathrm{XVa}+112.6^{\circ} \mathrm{C}$. The average value of the geothermal gradient is $2.23{ }^{\circ} \mathrm{C} / 100 \mathrm{~m}$, and the geothermal step is $46.19 \mathrm{~m} /{ }^{\circ} \mathrm{C}$. The North Guzar field was brought into development in 2007. Increasing production of hydrocarbons in 2007-2009 due to advance drilling of wells. The maximum production of gas and condensate was achieved in 2009 in volumes of 881225 and 163887 TEF. A sharp drop in production, starting from 2010, is associated with an increase in the water cut of good production, which led to a deterioration in the filtration-reservoir properties of the bottom-hole zone of wells and the operating stock, as well as a decrease in reservoir pressure from the initial 31.7 to $17.0 \mathrm{MPa}$. As of January 1, 2018, 13 wells have been drilled at the field, of which 7 are active (No. 1, 5, 9, 10,11,12,13), 1 well is awaiting overhaul, 
1 well is in the control fund and 4 wells have been abandoned. The development of the North Guzar field is characterized by the following technological indicators:

a. Cumulative gas production - 3426904 TUT or $32.37 \%$ of its approved reserves;

b. Extracted from the bowels of condensate 556084 TUT or $22.89 \%$ of its geological reserves;

c. Current reservoir pressure - $17 \mathrm{MPa}$, decreased by $53.6 \%$ in comparison with its initial indicator of $31.7 \mathrm{MPa}$.

The calculation of gas reserves by the volumetric method was carried out according to the formula.

$$
Q_{2}=S \cdot h \cdot K_{p} \cdot K_{g} \cdot\left(P_{p l} \cdot \alpha_{p l}-P_{0} \cdot \alpha_{0}\right) \cdot f \cdot \eta
$$

Where $S$ is the area of gas content, thousand $\mathrm{m}^{2}$;

$\mathrm{h} \quad$ : Effective gas-saturated thickness, $\mathrm{m}$

$\mathrm{K}_{\mathrm{p}} \quad$ : coefficient of porosity

$\mathrm{K}_{\mathrm{g}} \quad$ : gas saturation coefficient

Рпл, $\mathrm{P}_{\mathrm{o}} \quad$ : initial and final reservoir pressures $\left(P_{0}=1\right)$

$\alpha_{\mathrm{pl}}, \alpha 0 \quad$ : corrections for the deviation of real gases from the Boyle - Mariotte law ( $\left.\mathrm{a} 0=1\right)$

$f \quad$ : Temperature correction

$\eta \quad:$ : Conversion factor for dry gas.

Estimated parameters and gas reserves were taken in accordance with the report on the operational calculation of reserves of the North Guzar gas condensate field in the amount of 9618 thousand TEF approved by the Central Reserves Committee of the Uzbekneftegaz National Holding Company. Using the pressure drop method based on plotting the relationship between cumulative gas production and reduced reservoir pressure (defined as the ratio of reservoir pressure and gas compressibility factor), the value of gas reserves (P) was obtained equal to 6929.6 thous. TEF, which is $67.33 \%$ of the reserves calculated by the volumetric method $(\mathrm{V})$. In practice, there can be three cases of the ratio of gas reserves, calculated by volumetric and pressure drop method: $\mathrm{V}>\mathrm{P} ; \mathrm{V} \approx \mathrm{P}$ and $\mathrm{V}<\mathrm{P}$. The first case, in which $\mathrm{V}>\mathrm{P}$, is usually explained by incomplete drainage coverage of the gas-saturated volume of the reservoir and is often the basis for compaction of the wellbore grid density to increase the degree of gas recovery (Navon, 1998; Piattelli-Palmarini, 1989). The second case, when $\mathrm{V} \approx \Pi$, indicates an almost complete drainage coverage of the entire gas-saturated volume of the reservoir and the possibility of achieving the design value of gas recovery.

a. In the third case, when $\mathrm{V}<\mathrm{P}$, it becomes necessary to clarify gas reserves.

b. To clarify gas reserves and their reasons, it is advisable to use geological and mathematical models.

To increase the reliability of the reasons for the deviation of gas reserves calculated by the volumetric and pressure drop method, in our opinion, it is advisable to consider an additional criterion, which is the ratio of the current and initial reservoir pressures $\mathrm{P}$, equal to $P=P_{p l . t .} / P_{p l . n .}$. Where $\boldsymbol{P}_{\text {pl.t. }}$ the current reservoir pressure, $\mathrm{P}_{\text {pl.n. }}-$ Initial reservoir pressure. Here $Q\left(Q=\sum Q_{r} / Q_{H 3}\right.$ is the ratio of the cumulative gas production and it's approved initial reserves where $\Sigma \mathrm{Q}_{\mathrm{r}}$ is the cumulative gas production; $\mathrm{Q}_{\mathrm{H} 3}$ - initial gas reserves). When comparing the values of $\mathrm{P}$ and $\mathrm{Q}$, there can also be three cases:

a. At $\mathrm{P}>\mathrm{Q}$, the conclusion about the incomplete drainage coverage of the gas-saturated volume of the deposit and the need to revaluate the gas reserves is confirmed, since its value may be less than the approved one;

b. At $\mathrm{P} \approx \mathrm{Q}$, the conclusion about the complete coverage of the gas-saturated volume of the deposit by drainage and confirmation of the value of the established reserves is confirmed;

c. At $\mathrm{P}<\mathrm{Q}$, the conclusion about the need to recalculate gas reserves is confirmed, since its value may be greater than the approved ones.

The calculation of the gas reserves of this field by the statistical method was carried out according to various models. It has been established by numerical experiments that the highest indicators of the correlation coefficients are achieved for four of them. Calculations of the dependence of the logarithm of cumulative gas production $\left(\log \Sigma \mathrm{Q}_{\mathrm{g}}\right)$ on the development period $(\mathrm{t}$ ) show that this dependence is quite well (with a correlation coefficient $\mathrm{r}=0.9475$ ) described by the following mathematical model: 


$$
\left(\lg \sum Q_{g}\right)=0,0420 t^{2}+0,5218 t+2,6361
$$

A similar formula, but with a higher correlation coefficient equal to 0.9714 , describes the dependence of the annual gas production on its cumulative production $\left(\Sigma \mathrm{Q}_{\mathrm{g}}\right)$ :

$$
Q_{g}=0,2841 \sum Q_{g}{ }^{2}+0,9699 \sum Q_{2}+0,0629
$$

Along with them, the dependence of the logarithm of annual gas production on the development period (with a correlation coefficient of 0.9292 ) is also described:

$$
\lg Q_{r}=-0,0540 t^{2}+0,3838 t+2,8891
$$

Of all the considered statistical approaches, the model proposed by A.V. Kopytov stands out with the highest correlation coefficient, in the form of the dependence of the product of cumulative gas production on the development time. This relationship is very well described by a linear relationship with a correlation coefficient of $0.994 \%$.

$$
Q_{r} \cdot t=4,0449 t-5,041
$$

For all these options, a forecast of cumulative gas production for a 10-year period of field development was carried out. As established, the obtained values of cumulative gas production from 3450.9 to 3654.1 thousand TEF are very close, i.e. the discrepancy is only 5.56\% (Mahoney, 1995; Szekely et al., 2004).

\section{Results and Discussion}

At the same time, the average value of cumulative gas production is less than that calculated by the volumetric method by 6732.65 thousand TEF, i.e. is $34.58 \%$ of its value. The main reason for such a large discrepancy in the value of gas reserves according to these two methods is that the statistical models do not take into account possible changes in the implemented development system, in particular, the commissioning of a booster compressor station, changes in the technological mode of wells operation, drilling new gas production wells, etc. In the cases described, statistical models can be used to assess the effectiveness of the transformations carried out at the object in the implemented development system and geological and technical measures. The predicted data on the cumulative gas production of the Northern Guzar field according to statistical models are given in the table. The analysis showed that the deposits were discovered in the southeastern part. BHR are at various stages of development. The current rates of extraction from the initial geological reserves of hydrocarbons are gas $-1.0 \%$; condensate $-0.35 \%$ and oil $0.21 \%$, which indicates the low intensity of the development systems implemented at the fields.

Table 1

Forecast of cumulative gas production from the Northern Guzar field using statistical models

\begin{tabular}{llcc}
\hline № & Statistical model p/p & $\begin{array}{c}\text { Correlation } \\
\text { coefficient }\end{array}$ & $\begin{array}{c}\text { Cumulative gas production } \\
\text { during the development } \\
\text { period, thous. TEF }\end{array}$ \\
\hline 1 & $\lg \Sigma Q_{r}=-0,042-t^{2}+0,5218 t+2,6361$ & 0,9475 & 3654,1 \\
2 & $Q_{r}=-0,2841 \cdot \Sigma Q_{r}^{2}+0,9699 \cdot \Sigma Q+0,0629$ & 0,9714 & 3450 \\
3 & $\lg Q_{r}=-0,054 \cdot t^{2}+0,3138 \cdot t+2,8891$ & 0,9292 & 3492,3 \\
4 & $\Sigma Q_{r} \cdot t=4,0449 \cdot t-5,0411$ & 0,9949 & 3640.1 \\
\hline
\end{tabular}

The generally accepted indicator of the efficiency of the development systems implemented at the fields is the hydrocarbon recovery factors. As of January 1,2020, the average values of the gas, condensate and oil recovery factors were $0.626,0.429$ and 0.037 , respectively, which indicates the relatively low efficiency of the development systems implemented at the fields and the rather significant residual reserves of gas, condensate and oil in the 
developed fields. The main reason for the relatively small values of these coefficients is the low coverage of productive formations at the existing grid density of wells. By generalizing the geological and field data of long-term developed gas cap oil deposits, the dependences of the oil recovery factor on the density of the good grid are proposed, which make it possible to assess the need to compact the initial grid density to achieve the design oil recovery (Christian, 2020; Meza et al., 2020).

\section{Conclusion}

Geological and technical measures to improve the efficiency of the development of gas and gas condensate fields must be carried out on the basis of comparing gas reserves calculated by statistical, material balance and volumetric methods. At the same time, based on the difference in gas reserves according to the calculated statistical and material balance methods, the technological effect (additional produced gas and condensate) from the geological and technical measures taken is estimated, and the need for additional geological-technical measures.

\section{References}

Agzamov, A. Kh., \& Hayitov, O. G. (1999). Evaluation of the effectiveness of methods for regulating the development of oil fields using geological and statistical models. Bulletin of Tashkent State Technical University. T. No. 3. pp. 3-5.

Agzamov, A.A., \& Khayitov, O.G. (2010). Substantiation of the method for increasing the oil recovery factor based on the processing of geological data. Proceedings of higher educational institutions. Mining Journal, (8), 4751.Khayitov, O. G., \& Agzamova, S. A. (2014). Forecast of the final oil recovery factor of oil deposits with small reserves based on statistical models. Proceedings of higher educational institutions. Mining Journal, (7), 39-42.

Agzamova, A. Kh., Khayitova, O. G., \& Matniyazova, O. P. (2017). Solution of some problems in the development of gas fields based on the assessment of their reserves by various methods. Uzbek Journal of Oil and Gas. T .: NHC Uzbekneftegaz, (4), 32-35.

Akin, G., \& Hopelain, D. (1986). Finding the culture of productivity. Organizational Dynamics, 14(3), 19-32. https://doi.org/10.1016/0090-2616(86)90029-X

Akramov, B. Sh., Hayitov, O. G., \& Tabylganov, M. K. (2010). Methods for specifying the initial and residual recoverable oil reserves based on development data at a later stage. Proceedings of higher educational institutions. Mining Journal, (2), 20-24.

Aliev, Z.S., \& Bondarenko, V.V. (2002). Guidelines for the design of development of gas and gas-oil fields.

Burlutskaya, I. P., Khayitov, O. G., \& Zufarova, Sh. Kh. (2007). Oil and gas field geology. T .: "TALQIN". 384 s.

Cassiman, B., Golovko, E., \& Martínez-Ros, E. (2010). Innovation, exports and productivity. International Journal of Industrial Organization, 28(4), 372-376. https://doi.org/10.1016/j.ijindorg.2010.03.005

Christian, O. S. (2020). Competitive advantage and organisational performance in selected firms. International Research Journal of Management, IT and Social Sciences, 7(5), 1-12. https://doi.org/10.21744/irjmis.v7n5.965

G'afurovich, K. O. (2020). Current State And Ways To Improve The Efficiency Of Field Development In The South-Eastern Part Of The Bukhara-Khiva Region. The American Journal of Applied sciences, 2(09), $194-206$.

G'afurovich, K. O. (2020). Modern State And Methods Of Enhancing The Productivity Of Field Progress In The South-Eastern Part Of Bukhara-Khiva Region. The American Journal of Social Science and Education Innovations, 2(09), 423-432.

G'afurovich, K. O., Abdurashidovich, U. A., \& Ogli, B. A. O. (2020). Small Torch Progress In Prospects Gold Mining In Improving Countries. The American Journal of Interdisciplinary Innovations and Research, 2(09), 6572.

G'ofurovich, K. O., \& Abdurashidovich, U. A. (2021). Justification of rational parameters of transshipment points from automobile conveyor to railway transport. World Economics and Finance Bulletin, 1(1), 20-25.

G'ofurovich, K. O., Abdurashidovich, U. A., Ugli, M. U. F., \& Ugli, A. A. X. (2020). Justification Of The Need For Selective Development Of The Phosphorite Reservoir By Horizontal Milling Combines. The American Journal of Engineering and Technology, 2(11), 159-165.

Grozdev, B. P., Gritsenko, A. I., \& Kornilov, A. E. (1988). Operation of Gas and Gas Condensate Fields: A Reference Guide. Bosom.

Kadanoff, L. P. (1990). Scaling and universality in statistical physics. Physica A: Statistical Mechanics and its Applications, 163(1), 1-14. https://doi.org/10.1016/0378-4371(90)90309-G

Khayitov, O. G. (2019). On formation of abnormally high and abnormally low reservoir pressures. In VI International Scientific And Practical Conference.«Global science and innovations (pp. 82-86). 
Khayitov, O. G. (2020). Evolution Of Petroleum Stratum Efficiency By-Multi-Factor Regression Analysis. The American Journal of Engineering and Technology, 2(08), 79-84.

Khayitov, O. G. (2020). Evolution Of Petroleum Stratum Efficiency By-Multi-Factor Regression Analysis. The American Journal of Engineering and Technology, 2(08), 79-84.

Khayitov, O. G., Nabieva, N. K., \& Makhmudov Sh, N. (2013). Estimation of the degree of influence of the grid density of wells on the oil recovery coefficient of sub-gas oil deposits. Ural. Proceedings of universities. Mining journal,(6), 46-50.

Khayitov, O. G., Yuldoshev, \& A. F., Zhuraev, S. Zh. (2018). Determination of the final oil recovery of reservoirs by the method of multivariate regression analysis. Innovative education is a factor in increasing the competitiveness of the oil and gas industry of the Republic of Uzbekistan. T .: Branch of the Gubkin Russian State University of Oil and Gas. p.202-204.

Lifson, N., \& McClintock, R. (1966). Theory of use of the turnover rates of body water for measuring energy and material balance. Journal of theoretical biology, 12(1), 46-74. https://doi.org/10.1016/0022-5193(66)90185-8

Mahoney, J. T. (1995). The management of resources and the resource of management. Journal of business research, 33(2), 91-101. https://doi.org/10.1016/0148-2963(94)00060-R

Mayer, D. G., \& Butler, D. G. (1993). Statistical validation. Ecological modelling, 68(1-2), 21-32. https://doi.org/10.1016/0304-3800(93)90105-2

Meza, W. E. Y., Saltos, E. R. R., Loor, B. M. V., \& Solorzano, M. J. P. (2020). Technological tools as didactic resource for various educational modalities. International Research Journal of Management, IT and Social Sciences, 8(1), 9-18. https://doi.org/10.21744/irjmis.v8n1.1079

Navon, I. M. (1998). Practical and theoretical aspects of adjoint parameter estimation and identifiability in meteorology and oceanography. Dynamics of atmospheres and oceans, 27(1-4), 55-79. https://doi.org/10.1016/S0377-0265(97)00032-8

Piattelli-Palmarini, M. (1989). Evolution, selection and cognition: From "learning" to parameter setting in biology and in the study of language. Cognition, 31(1), 1-44. https://doi.org/10.1016/0010-0277(89)90016-4

Suchkov, B.M. (2006). Horizontal wells.

Szekely, A., Jacobsen, T., D'Amico, S., Devescovi, A., Andonova, E., Herron, D., ... \& Bates, E. (2004). A new online resource for psycholinguistic studies. Journal of memory and language, 51(2), 247-250. https://doi.org/10.1016/j.jml.2004.03.002

Xayitov, O. G., \& Akhrorova, H. (2002). Methods of substantiation of the duration of the identified oil reserves of the assemblies used. Technology stars. T. №3. pp.92-94.

Xayitov, O. G., Agzamov, A. A., \& Bobomurodov, U. Z. (2019). Xayitov O.G., Agzamov A.A., Bobomurodov U.Z. (2019). Results of utochneniya koeffitsienta vytesneniya nefti vodoy dlya geologo-fizicheskix usloviy mestorozhdeniya Shakarbulak. Uzbekistan Mining Bulletin. Navoi. №2. pp.40-41.

Xu, Y., Adefidipe, O., \& Dehghanpour, H. (2016). A flowing material balance equation for two-phase flowback analysis. Journal of Petroleum Science and Engineering, 142, 170-185. https://doi.org/10.1016/j.petrol.2016.01.018 